\title{
Studying on Liquid Phase Cyclohexane Oxidation Enhanced by Oxalic Acid: Pertinent Response by Long-Lasting Challenge
}

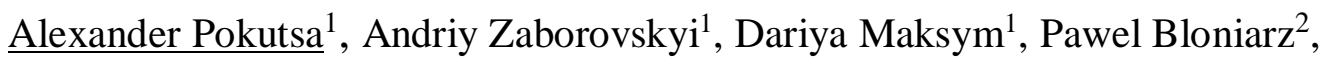 \\ and Jacques Muzart ${ }^{3}$
}

1. Department of Physical Chemistry of Fossil Fuels Institute of Physical Organic Chemistry and Coal Chemistry NAS of Ukraine, UKRAINE, Lviv, 79060, Naukova Str., 3A, E-mail: apokutsa@ukr.net

2. Department of Chemistry, Rzeszow University of Technology, POLAND, Rzeszow, P.O. Box 85, 35-959, Al. Powst. Warszawy, 6, E-mail: bloniarz@ prz.edu.pl

3. Université de Reims Champagne-Ardenne, Institut de Chimie Moléculaire de Reims, UMR 7312, UFR des Sciences Exactes et Naturelles, FRANCE, BP 1039, 51687 Reims Cedex 2, E-mail: jacques.muzart@ univ-reims.fr

A new effective protocol for oxidation of cyclohexane in acetonitrile at $40{ }^{\circ} \mathrm{C}$ and atmospheric pressure into cyclohexanol, cyclohexanone and cyclohexylhydroperoxide using $\mathrm{H}_{2} \mathrm{O}_{2}$ as sustainable oxidant, vanadyl(IV)-acetylacetonate as starting catalyst, oxalic acid and glyoxal as activating additives is presented with some reaction mechanism proposals.

Mild oxidation, cyclohexane, vanadyl(IV)-acetylacetonate, $\mathrm{H}_{2} \mathrm{O}_{2}$, oxalic acid, glyoxal, process activators, mechanism.

\section{Introduction}

Despite the extensive efforts aim to elaborate of new effective and energy-spared protocol for the cyclohexane oxidation the denoted problem remains one among the biggest challenges of contemporary chemistry. It refer to the extended application of oxidized products, i.e. cyclohexanol, cyclohexanone and cyclohexylhydroperoxide as precursors in artificial fibers industry (Nylon 6 and 6,6). Indeed, these products are used to manufacture as much as $2.3 \times 10^{6} \mathrm{~T}$ adipic acid and $4.4 \times 10^{6} \mathrm{~T}$ of $\varepsilon$-caprolactam per year [1]. On the other hand, what is even more important, study by activation the extraordinary strong $\mathrm{C}-\mathrm{H}$ bonds of $\mathrm{C}_{6} \mathrm{H}_{12}(\mathrm{BDE}=98 \mathrm{kcal}$ $\mathrm{mol}^{-1}$ ) would result in new fundamental knowledge be useful for elaboration the modern methods of others industrially-meaningful substrates functionalization. The actual study reports that the $\mathrm{VO}(\mathrm{acac})_{2}(\mathbf{1})$ catalyzed cyclohexane oxidation by $\mathrm{H}_{2} \mathrm{O}_{2}$ at mild conditions is notably improved by using both glyoxal and it oxidized descendant oxalic acid (3). The putative mechanism the denoted additives influence is elucidated by GLC, UV-Vis, CV, EPR, ESI-MS.

Kinetics and mechanism of $\mathrm{C}_{6} \mathrm{H}_{12}$ oxidation in presence of glyoxal and oxalic acid

In the absence of 2 , the reaction of $\mathrm{C}_{6} \mathrm{H}_{12}$ with $\mathrm{H}_{2} \mathrm{O}_{2}$ (1 equiv.by substrate) at $40{ }^{\circ} \mathrm{C}$

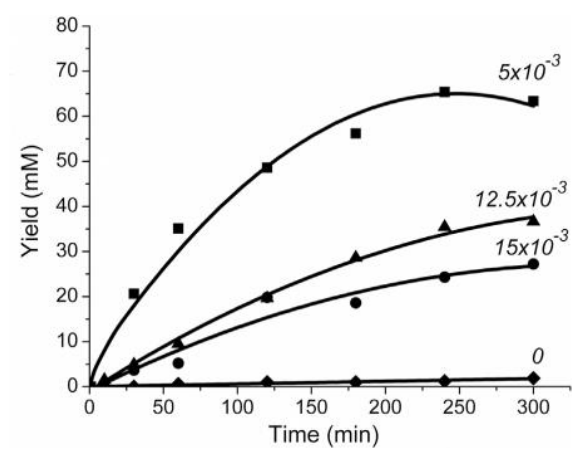

Fig. 1. Kinetics of sum products accumulation. Concentration of $\mathbf{2}$ is given in $\mathrm{M}$ above of each curve.

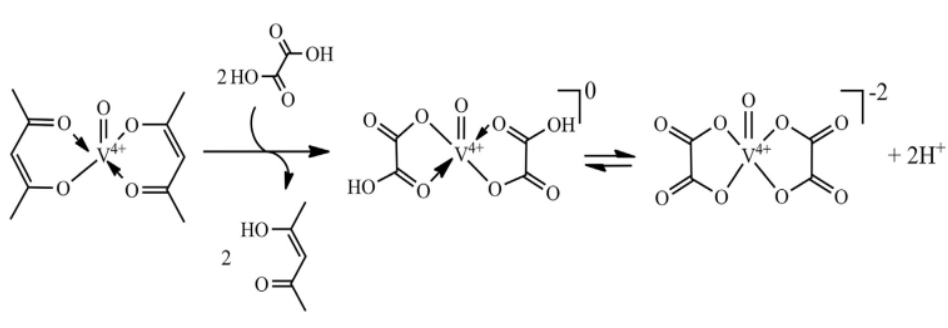

Scheme 1. The plausible structures of $1+2$ interaction. 
requires at least $(0.3 \div 0.6) \times 10^{-3} \mathrm{M}$ of 1 to generate the detectable amounts of products $\mathrm{C}_{6} \mathrm{H}_{11} \mathrm{OH}, \mathrm{C}_{6} \mathrm{H}_{10} \mathrm{O}$ and $\mathrm{C}_{6} \mathrm{H}_{11} \mathrm{OOH}$ (Fig. 1). Below of this range the yield of aimed products was ignorable (curve 1, Fig. 1) and the level of $\mathrm{H}_{2} \mathrm{O}_{2}$ utilization $\left(\Delta \mathrm{H}_{2} \mathrm{O}_{2}\right)$ and it effectiveness $\left(E f f_{\mathrm{H} 2 \mathrm{O} 2}\right)$ was $<1 \%$ and $>90 \%$, respectively (Table 1). The addition of 2 into the reaction mixture contained even $0.06 \mathrm{mM}$ of 1 resulted in a four-fold increasing of cyclohexane conversion (even in respect to the 10 times higher catalyst concentration of $\mathbf{2}$-free experiment) concomitant with the Eff $_{\mathrm{H} 2 \mathrm{O} 2}$ growing (entries 2 and 7, Table 1). Simultaneous decreasing the catalyst and substrate initial load (Table 1, entries 4 and 8) lead to enhancing the conversion, turnover number (TON), and process efficiency from $5 \%$ (entry 4) to $30 \%$ (entry 8) and and $E f f_{\mathrm{H} 2 \mathrm{O} 2}$ from $8 \%$ to $16 \%$, respectively. Due to the instrumental analysis the initial $\mathbf{1}$ as well as the originated in situ $\mathrm{VO}(\text { oxalate })_{2}$ (Scheme 1, Fig. 2, 3) can interact with $\mathrm{H}_{2} \mathrm{O}_{2}$ produce the $\mathrm{VO}(\eta-\mathrm{O})_{2}$-based species.

Table 1. The effect of $\mathbf{2}$ additives in 1-catalyzed cyclohexane oxidation. ${ }^{a}$

\begin{tabular}{|c|c|c|c|c|c|c|c|c|c|}
\hline \multirow{2}{*}{ Entry } & 1 & 2 & \multirow{2}{*}{$\begin{array}{c}\Delta \mathrm{C}_{6} \mathrm{H}_{12} \\
\%\end{array}$} & \multicolumn{3}{|c|}{ Selectivity, mol\% } & \multirow{2}{*}{ TON } & \multirow{2}{*}{$\begin{array}{c}\Delta \mathrm{H}_{2} \mathrm{O}_{2}{ }^{\mathrm{b}}, \\
\%\end{array}$} & \multirow{2}{*}{$\begin{array}{c}E f f_{\mathrm{H} 2 \mathrm{O} 2}{ }^{\mathrm{c}}, \\
\%\end{array}$} \\
\hline & \multicolumn{2}{|c|}{$\times 10^{3}, \mathrm{M}$} & & $\overline{\mathrm{C}_{6} \mathrm{H}_{11} \mathrm{OH}}$ & $\mathrm{C}_{6} \mathrm{H}_{10} \mathrm{O}$ & $\mathrm{C}_{6} \mathrm{H}_{11} \mathrm{OOH}$ & & & \\
\hline 1 & 0.06 & - & $<0.1$ & - & - & - & - & $<1$ & $>90$ \\
\hline 2 & 0.6 & - & 1.2 & 33 & 62 & 5 & 23 & 48 & 4.2 \\
\hline 3 & 0.6 & 1.0 & 1.7 & 1 & 8 & 91 & 51 & 52 & 6.5 \\
\hline 4 & 0.6 & 15 & 5.3 & 48 & 7 & 45 & 169 & 96 & 8.4 \\
\hline 5 & 0.6 & 50 & 7.6 & 43 & 13 & 44 & 253 & 90 & 13.2 \\
\hline 6 & 0.6 & 150 & 5.2 & 47 & 10 & 43 & 173 & 80 & 9.9 \\
\hline 7 & 0.06 & 50 & 5.1 & 23 & 25 & 43 & 1516 & 25 & 32.4 \\
\hline $8^{\mathrm{d}}$ & 0.06 & 15 & 30 & 22 & 44 & 34 & 944 & 34 & 15.7 \\
\hline $9^{e}$ & 0.06 & 30 & 0.2 & 29 & 29 & 42 & 56 & 5 & 6.8 \\
\hline
\end{tabular}
tests, the products selectivity was above 90\%). ${ }^{b}$ Amount of $\mathrm{H}_{2} \mathrm{O}_{2}$ consumed. ${ }^{c}$ Eff $\mathrm{H}_{2} \mathrm{O}$ is the ratio of stoichiometric (by products yield) amount of $\mathrm{H}_{2} \mathrm{O}_{2}$ divided by the $\mathrm{H}_{2} \mathrm{O}_{2}$ consumed. ${ }^{d}\left[\mathrm{C}_{6} \mathrm{H}_{12}\right]_{0}=$ $0.18 \mathrm{M}$. ${ }^{e}$ Acetic acid has been used instead of 2 . The $\Delta \mathrm{C}_{6} \mathrm{H}_{12}$ (substrate conversion) values match well with the products yield due to the almost $100 \%$ process selectivity.

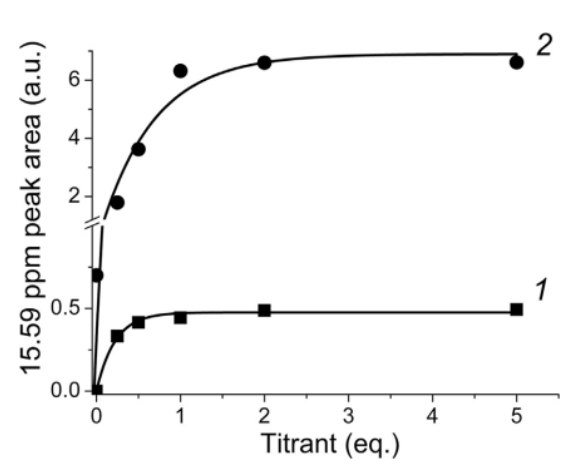

Fig. 2. Kinetics of enol $\mathrm{OH}$ peak (15.59 ppm) growing during of $1\left(1.5 \times 10^{-3} \mathrm{M}\right)$ solution titration by $\mathrm{H}_{2} \mathrm{O}_{2}(1)$ and $2(2), \mathrm{CD}_{3} \mathrm{CN}, 20{ }^{\circ} \mathrm{C}$.

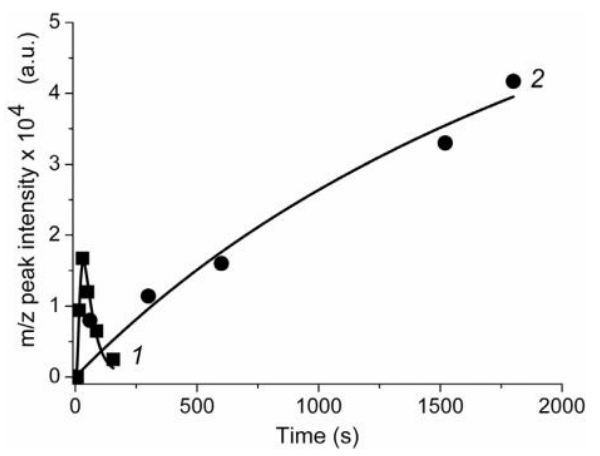

Fig. 3. Time-traces of $\left[\mathrm{VO}(\eta-\mathrm{O})_{2}(\text { acac })\right]^{+}$,

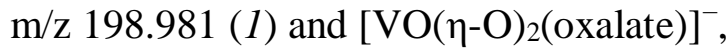
$\mathrm{m} / \mathrm{z} 186.908$ (2) species accumulation.

\section{Conclusion}

Privilege formation of $\mathrm{VO}(\eta-\mathrm{O})_{2}$ species in $\mathbf{1}+\mathbf{2}$ oxidation is responsible for the revealed effect.

[1] J. O. Metzger, M. Eissen, "Concepts on the contribution of chemistry to a sustainable development. Renewable raw materials", C. R. Chimie, 7, pp. 569-581, 2004. 